\title{
Improving patient discharge and reducing hospital readmissions by using Intervention Mapping
}

Gijs Hesselink ${ }^{1 *}$, Marieke Zegers ${ }^{1}$, Myrra Vernooij-Dassen ${ }^{1,2,3}$, Paul Barach ${ }^{4,5,6}$, Cor Kalkman ${ }^{4}$, Maria Flink ${ }^{7,8}$, Gunnar Öhlén ${ }^{9,10}$, Mariann Olsson ${ }^{7,8}$, Susanne Bergenbrant ${ }^{11}$, Carola Orrego ${ }^{12}$, Rosa Suñol ${ }^{12}$, Giulio Toccafondi ${ }^{13}$, Francesco Venneri ${ }^{13}$, Ewa Dudzik-Urbaniak ${ }^{14}$, Basia Kutryba ${ }^{14}$, Lisette Schoonhoven ${ }^{1}$, Hub Wollersheim ${ }^{1}$ and on behalf of the European HANDOVER Research Collaborative

\begin{abstract}
Background: There is a growing impetus to reorganize the hospital discharge process to reduce avoidable readmissions and costs. The aim of this study was to provide insight into hospital discharge problems and underlying causes, and to give an overview of solutions that guide providers and policy-makers in improving hospital discharge.
\end{abstract}

Methods: The Intervention Mapping framework was used. First, a problem analysis studying the scale, causes, and consequences of ineffective hospital discharge was carried out. The analysis was based on primary data from 26 focus group interviews and 321 individual interviews with patients and relatives, and involved hospital and community care providers. Second, improvements in terms of intervention outcomes, performance objectives and change objectives were specified. Third, 220 experts were consulted and a systematic review of effective discharge interventions was carried out to select theory-based methods and practical strategies required to achieve change and better performance.

Results: Ineffective discharge is related to factors at the level of the individual care provider, the patient, the relationship between providers, and the organisational and technical support for care providers. Providers can reduce hospital readmission rates and adverse events by focusing on high-quality discharge information, wellcoordinated care, and direct and timely communication with their counterpart colleagues. Patients, or their carers, should participate in the discharge process and be well aware of their health status and treatment. Assessment by hospital care providers whether discharge information is accurate and understood by patients and their community counterparts, are important examples of overcoming identified barriers to effective discharge. Discharge templates, medication reconciliation, a liaison nurse or pharmacist, regular site visits and teach-back are identified as effective and promising strategies to achieve the desired behavioural and environmental change.

Conclusions: This study provides a comprehensive guiding framework for providers and policy-makers to improve patient handover from hospital to primary care.

Keywords: Patient handoff, Patient discharge, Patient readmission, Intervention mapping, Adverse events

\footnotetext{
* Correspondence: gijs.hesselink@radboudumc.nl

${ }^{1}$ Radboud University Medical Center, Scientific Institute for Quality of Healthcare (IQ healthcare), 114 IQ healthcare, P.O. Box 9101, 6500 HB, Nijmegen, The Netherlands

Full list of author information is available at the end of the article
} 


\section{Background}

Patients still experience needless harm and often struggle to have their voices heard, processes are not as efficient as they could be, and costs continue to rise at alarming rates while quality issues remain. A shorter length of hospital stay, the decrease in work-hours of health care providers, and the increasing number of patient transitions between departments and institutions requires effective patient handovers, especially those of frail patients with comorbidities [1]. Continuity of care at patient discharge from the hospital is a critical aspect of high quality patient care $[2,3]$. Highly reliable care requires close cooperation between care providers across organisational boundaries, thereby establishing an interdisciplinary network [4]. Unfortunately, incomplete or incorrect information and communication errors between hospital care providers and the multiple receiving parties often increase the chance of adverse events. These may ultimately lead to life threatening situations, avoidable treatments, unplanned re-hospitalisations [5,6], and extra costs [7-9].

Although studies have identified discharge problems in the social, organisational, linguistic and technical context [10-12], there is insufficient, evidence driven insights into more effective solutions. The effectiveness of most interventions is highly variable and limited in daily practice. Explanations for these disappointing results include the difficulty of changing providers behaviour and existing practices, non-optimal intervention strategies, inadequate resources devoted to evaluating the impact of interventions, and inadequate methods to design and evaluate interventions [13-15]. A systematic approach for translating discharge problems into customised solutions is lacking. Many clinical intervention developers select their strategies intuitively. Effective interventions need to be theory- and evidence based, and targeted at specific behavioural and environmental factors $[16,17]$.

The aim of our study was to systematically develop a guiding framework to more effective design of interventions that support care providers and policy-makers to improve patient handovers from the hospital to primary care.

\section{Methods}

Intervention mapping (IM) is a systematic, iterative sixstep process that helps to develop an intervention, based on theoretical, empirical and practical information [18]. The steps are summarised in Table 1. IM was originally used effectively in the health promotion domain to develop programs for smoking cessatation [19], stroke prevention [20], asthma management [21], HIV prevention [22], and leg ulcer management [23]. We modified the IM terminology in order to apply it to the quality improvement domain.

\section{Step 1: Problem analysis}

We structured the problem analysis by using the PRECEDE PROCEED model [24] (see Additional file 1), to analyse and describe the scale, causes, and consequences of the health problem and to identify the target population.

\section{Procedure and participants}

A literature search on the frequency and consequences of ineffective hospital discharge problems was performed [25]. We performed a large qualitative study on patient handovers between acute care hospitals and primary care in five countries, i.e. The Netherlands, Spain, Poland, Sweden, and Italy, to identify the behavioural and environmental determinants influencing ineffective hospital discharge [10-12]. The study adhered to the RATS (Relevance, Appropriateness, Transparency, Soundness) guidelines for qualitative studies. Data collection and analysis consisted of multi-method qualitative research including individual and focus group interviews [26], process maps, artefact analyses [10-12], and Ishikawa diagrams [27] (Table 1). The discharged patients and their care providers were recruited using general and country-specific inclusion criteria (see Additional file 2). The study was approved by the ethics committee of the University Medical Center Utrecht - Medical Ethics Committee. Patients were asked for informed consent.

\section{Step 2: Identify intervention outcomes, performance objectives and change objectives}

In step 2, we identified the desired outcomes of the intervention and formulated specific performance objectives for the target population, such as writing a complete, accurate and timely discharge letter by the hospital physician. This resulted in a step-by-step checklist of what needs to be accomplished in order to obtain the desired outcomes [28].

It is important to identify what steps need to be tweaked in order to affect the performance objective, and ultimately the intervention outcome [28]. We identified the most important determinants (e.g., lack of knowledge and understanding between hospital and primary care providers) that need to be changed and combined these with performance objectives to formulate our change objectives. These change objectives specified who and what will change as a result of the intervention.

\section{Procedure and participants}

A literature search of the desired outcomes of the intervention was conducted [25]. The performance objectives and matrices of change objectives were discussed in a multidisciplinary study panel $(n=5)$ that included experts in health-, social- and organisational sciences. Members of the European HANDOVER Research 
Table 1 Intervention mapping steps, objectives and methods*

\begin{tabular}{|c|c|c|c|}
\hline \multicolumn{2}{|c|}{ Steps } & \multirow{2}{*}{$\begin{array}{l}\text { Objectives } \\
\text { - Gain insight into health problem, quality of care, } \\
\text { underlying causes and target population }\end{array}$} & \multirow{2}{*}{$\begin{array}{l}\text { Methods } \\
\text { - Problem analysis using PRECEDE-PROCEED model; }\end{array}$} \\
\hline 1. & Problem analysis & & \\
\hline & & & - Analysis based on: \\
\hline & & & - Literature research \\
\hline & & & - Individual interviews $(n=321)$ \\
\hline & & & - Focus group interviews $(n=26)$ \\
\hline & & & - Process maps $(n=5)$ \\
\hline & & & - Artifact analyses $(n=5)$ \\
\hline & & & - Ishikawa (fishbone) diagrams $(n=5)$ \\
\hline \multirow[t]{4}{*}{2.} & \multirow{4}{*}{$\begin{array}{l}\text { Identify intervention outcomes, } \\
\text { performance objectives and } \\
\text { change objectives }\end{array}$} & - State intervention outcomes & \multirow{2}{*}{$\begin{array}{l}\text { - Use evidence from literature and empirical data } \\
\text { from problem analysis (step 1) }\end{array}$} \\
\hline & & - Specify performance objectives & \\
\hline & & - Select important and changeable determinants & $\begin{array}{l}\text { - Input from experts in the field of patient } \\
\text { handover (healthcare providers, and } \\
\text { organizational, social and health scientists) }\end{array}$ \\
\hline & & $\begin{array}{l}\text { - Develop matrices with change objectives based on } \\
\text { performance objectives and determinants of } \\
\text { suboptimal hospital discharge }\end{array}$ & \\
\hline \multirow[t]{6}{*}{3.} & \multirow{6}{*}{$\begin{array}{l}\text { Select theory-based methods } \\
\text { and strategies }\end{array}$} & - Identify and select theoretical methods & - Literature search on theory-based methods \\
\hline & & $\begin{array}{l}\text { - Select evidence-based interventions and design of } \\
\text { practical strategies }\end{array}$ & \multirow[t]{2}{*}{ - Input from experts $(n=220)$} \\
\hline & & $\begin{array}{l}\text { - Ensure that interventions and strategies address } \\
\text { change objectives }\end{array}$ & \\
\hline & & & $\begin{array}{l}\text { - Systematic literature review on evidence based } \\
\text { discharge interventions }\end{array}$ \\
\hline & & & $\begin{array}{l}\text { - Additional search for experience based practical } \\
\text { strategies }\end{array}$ \\
\hline & & & $\begin{array}{l}\text { - Matching methods and practical strategies with } \\
\text { determinants and performance objectives (step } 1 \\
\text { and 2) }\end{array}$ \\
\hline 4. & Develop an intervention & - Provide suggestions for developing an intervention & - Input from literature search and experts \\
\hline 5. & Implementation & $\begin{array}{l}\text { - Provide suggestions for writing an implementation } \\
\text { plan }\end{array}$ & $\begin{array}{l}\text { - Literature search of implementation strategies } \\
\text { and tools }\end{array}$ \\
\hline 6. & Evaluation & - Provide suggestions for writing an evaluation plan & $\begin{array}{l}\text { - Literature search on methods for effect and } \\
\text { process evaluation on complex interventions }\end{array}$ \\
\hline
\end{tabular}

*Adapted from Bartholomew et al. [18].

Collaborative ( $\mathrm{n}=15$ experts in the field of handover and health care providers) prioritised using a survey the large number of determinants of importance on a 5 -point Likert scale.

Step 3: Selection of theory-based methods and strategies We selected theory-based methods that relate to the change objectives in step 2 . These methods were required to change the behavioural and environmental determinants of ineffective hospital discharge. Subsequently, these methods were translated into practical strategies.

\section{Procedure and participants}

Theory-based methods were identified from our literature search and mainly found in overviews provided by
Bartholemew et al. [18], Achterberg et al. [29], and Grol et al. [30]. A total of 220 international researchers, policy-makers and regulators in the field of quality and safety in healthcare, healthcare providers and patient representatives were consulted about their experiences with successful strategies or promising ideas during three expert meetings in 2010-2011 [31]. A systematic review of randomised controlled trials (RCTs) of the effects of discharge interventions provided an overview of evidence-based strategies [32]. The systematic review was performed in accordance with the PRISMA guidelines. An additional literature search was performed to identify promising strategies that were not included in the systematic review (e.g., evaluated with a weaker study design than RCTs) or not evaluated yet (e.g., local 
initiatives). The strategies were selected by the study panel after 11 iterative discussion sessions based on the findings from the systematic review, the experiences of the experts and the additional literature search.

\section{Step 4: Develop an intervention}

In this step, we provide suggestions for the design of the intervention by considering the target group and local setting [18]. The intervention studies identified in step 3 were classified independently by two researchers (GH and MZ) according to the Oxford Centre for Evidence-Based Medicine - Levels of Evidence from 2009 onward [33].

\section{Steps 5 and 6: Implementation and Evaluation}

We made suggestions for developing an implementation plan for accomplishing program adoption, and for evaluating the effects and feasibility of the intervention program. The suggestions were based on literature regarding effective implementation strategies [17,30,34-36], existing implementation toolboxes [37,38], and a literature review on methods to evaluate complex interventions in health care $[35,39,40]$.

\section{Results}

\section{Step 1: Problem analysis}

The health problem and the underlying causes are presented in Figure 1. The published studies demonstrate that one in five patients experience an adverse event within 3 weeks after hospital discharge, of which one in three was considered preventable [41]. Three per cent of the adverse events led to permanent disability, including death. The one month unplanned readmission rates varied between 13\% [42], and 20\% [43]. Unnecessary hospital readmissions lead to considerable suffering, harm and extra costs. Friedman and Basu estimated hospital costs for preventable readmissions during 6 months at about $\$ 730$ million [7]. Jencks estimated total hospital costs at $\$ 44$ billion per year for rehospitalisations among Medicare patients within 30 days of hospital discharge [44].

We found that ineffective handovers that lead to patient readmissions are caused by poor information exchange, poor coordination of care and poor communication between hospital and primary care providers, and between care providers and patients. The underlying causes include attitudinal and behavioural factors (e.g., lack of understanding of the needs of the counterpart, a distant relationship and a lack of collaborative attitude between

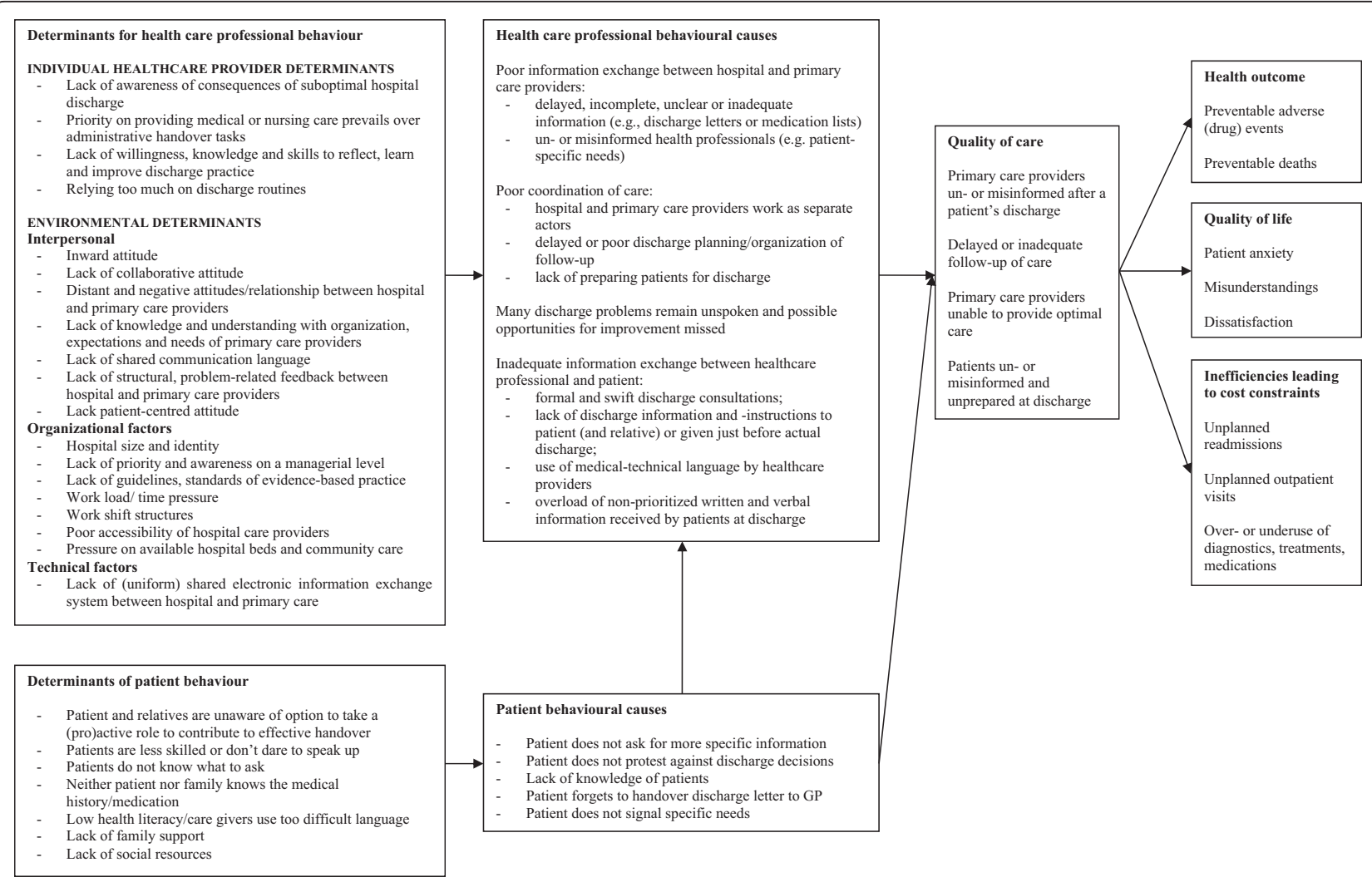

Figure 1 Model of suboptimal hospital discharge: overview of the health problem, causes and their determinants. 
hospital and primary care providers), organisational factors (e.g., lack of guidelines), technical factors (lack of a shared electronic information system) or patient factors (e.g., patients are less skilled or don't dare to speak up). All the identified causes and their underlying factors are summarised in Figure 1.

\section{Step 2: Matrices of change objectives Intervention outcomes and performance objectives}

Measurable and feasible endpoints to evaluate the discharge process are hospital readmission rates and adverse events rates after the hospital discharge.

All performance objectives are listed in Table 2. It is important for healthcare providers to transfer highquality discharge information to primary care providers and patients. For example, using discharge letters that are complete (i.e., no redundant/irrelevant or missed information), accurate and understandable (i.e., structured presentation of information, explanation of abbreviations jargon), and patients being informed at discharge in plain language. Regarding coordination of care, healthcare providers are expected to have organised and accurate follow-up services at patient's discharge in a timely manner and tailored to the patient's preferences and

Table 2 Performance objectives for healthcare providers and patients

\begin{tabular}{|c|c|}
\hline Healthcare providers & \\
\hline \multirow[t]{3}{*}{ Discharge information } & 1a. Complete discharge information \\
\hline & 1b. Clear discharge information \\
\hline & 1c. Accurate discharge information \\
\hline \multirow[t]{3}{*}{ Coordination of care } & $\begin{array}{l}\text { 2a. Ensure that follow-up services are being } \\
\text { organized at actual discharge }\end{array}$ \\
\hline & $\begin{array}{l}\text { 2b. Tailor follow-up care to patient needs } \\
\text { and preferences }\end{array}$ \\
\hline & 2c. Organize timely and accurate follow-up \\
\hline \multirow[t]{4}{*}{$\begin{array}{l}\text { Discharge } \\
\text { communication }\end{array}$} & $\begin{array}{l}\text { 3a. Seek direct/personal contact with } \\
\text { primary care counterpart }\end{array}$ \\
\hline & $\begin{array}{l}\text { 3b. Discharge information easily accessible } \\
\text { to counterpart care providers and patients } \\
\text { (and relatives) }\end{array}$ \\
\hline & $\begin{array}{l}\text { 3c. Exchange discharge information on time } \\
\text { to primary care counterparts }\end{array}$ \\
\hline & $\begin{array}{l}\text { 3d. Inform patient (and relatives) personally } \\
\text { and in timely manner }\end{array}$ \\
\hline \multicolumn{2}{|l|}{ Patients } \\
\hline $\begin{array}{l}\text { Participation in discharge } \\
\text { process }\end{array}$ & $\begin{array}{l}\text { 4. Contribute, if capable, to the continuity of } \\
\text { care in the discharge process }\end{array}$ \\
\hline $\begin{array}{l}\text { Awareness of health } \\
\text { status and treatment }\end{array}$ & $\begin{array}{l}\text { 5. Well aware about medical history and } \\
\text { medication use, diagnosis/indication and } \\
\text { (side) effects of the treatment, post } \\
\text { discharge appointments, scheduled tests } \\
\text { and (pending) test results }\end{array}$ \\
\hline
\end{tabular}

psychosocial needs (e.g., assessment of home setting, social risks and support). Examples of performance objectives for discharge communication are hospital care providers being accessible for primary care providers or patients and exchanging discharge information in time to support primary care providers or patients.

Patients are, if capable, expected to contribute to the continuity of care by participating in the discharge process (e.g., by handing over a discharge letter to their GP after being discharged), and by being well aware of their health status (e.g., medical and medication history) and treatment plan.

\section{Selected determinants and change objectives}

The most important determinants (as perceived by experts in the field of patient handovers and described in step 2 of the methods) were classified according to the individual professional, interpersonal, organisational, technical and patient levels. Combining the performance objectives with the selected determinants resulted in two matrices with change objectives for healthcare providers and patients, which interventions need to target. The matrices are presented in Additional file 3.

\section{Step 3: Selecting theory-based methods and strategies}

Our literature review identified a raft of change methods, such as knowledge transfer, active listening and guided practice from the Social Cognitive Theory (SCT) [45], consciousness raising from the Transtheoretical Model [46,47], shifting perspectives and interpersonal contact from the Intergroup Contact Theory [48] and standardised working processes from the SCT and Rational Decision-making theories [30] as influencers of the behavioural and environmental determinants of ineffective hospital discharge. Goal-setting and implementation intentions were derived from theories of Goal Directed Behaviour [49,50], and multi-disciplinary collaboration and case management from theories of Integrated Care [51]. These theory-based methods were subsequently operationalised into practical strategies and corresponding activities and materials for the targeted population [52-76] as shown in Table 3.

\section{Step 4: Develop an intervention}

We formulated a wide variety of change objectives at the individual clinician and patient levels, the interpersonal level, organisational and technical levels that need to be considered in order to tackle ineffective handovers at discharge more reliably (Additional file 3). Given these change objectives the intervention likely needs to be multi-faceted and needs to be tailored to the needs encountered in the local setting. Table 3 shows a framework with examples of strategies and related materials and activities guiding healthcare providers and policy makers in 
Table 3 Overview of change determinants, theory-based methods, strategies and practical applications, and evidence

\section{Examples of activities} and materials
References* Evidencet

\begin{tabular}{l} 
Determinants and \\
change objectives \\
\hline Individual healthcare provider
\end{tabular}

Aware of the consequences of suboptimal hospital discharge

Perceive handover administrative tasks as important part of patient discharge care and act accordingly

Interpersonal

Outward focus by hospital-based care providers to ensure continuity of care after discharge

Hospital and primary care provider collaborative during the discharge process

\begin{tabular}{ll}
$\begin{array}{l}\text { Theory-based } \\
\text { methods }\end{array}$ & $\begin{array}{l}\text { Examples of strategies/ } \\
\text { practical applications }\end{array}$ \\
\hline $\begin{array}{l}\text { Knowledge } \\
\text { transfer/Active }\end{array}$ & $\begin{array}{l}\text { Education in the medical and } \\
\text { learning }\end{array}$
\end{tabular}

Stimulus control/ Reinforcement

Punishment by financial penalties; visual electronic reminders follow-up

Integrated care/ Case conference Intergroup contact/ Case management
Integrated care Post-discharge monitoring of

52

$3 a$

and exercises with workbook

and online materials (e.g.,

communication skills and

discharge letter requirements)

Red, orange and green flags

indicating status of discharge

letter and planning; visualization

of deadline for sending discharge

letter

Standard post-discharge telephone evaluate follow-up, provide additional instructions and answer questions

Hospital or community-based

face-to-face or telephone meetings between hospital and primary care providers

Liaison person

Designated care provider

coordinating hospital discharge,

follow-up care and the

communication between

hospital and primary care providers

Team building/ Meetings between hospital and Focus group sessions, regular Intergroup primary care providers to meetings and site visits to get understanding of the contact/ Shifting increase mutual understanding perspective and respect between both parties

expectations and needs

Structural, problem-related feedback between hospital and primary care providers

Patient-centered attitude

Modeling/ Use of plain, patient-friendly, Individualization nonmedical language

Active listening Teach back

Standardized

working

processes

Means to facilitate and

\section{Organizational}

Guidelines and standards of evidence-based practice stimulate structural feedback to know each other, to learn each other's organization and needs and to identify improvement opportunities

Standard feedback form and return envelop along with discharge letter send to primary care providers

Discharge summary in language that is understandable for patients and relatives

Care provider checks if patients received all discharge information needed and if they understood the received information
Templates, formats, required (web-based) fields, clinical decision-support, pick lists
Standardized discharge letter (e.
g. templates, formats)
Standardized discharge
planning

Medication reconciliation

Guidelines, protocols, checklists for follow-up

Standardised medication reconciliation checklist/medication discrepancy 
Table 3 Overview of change determinants, theory-based methods, strategies and practical applications, and evidence (Continued)

\begin{tabular}{|c|c|c|c|c|c|}
\hline \multicolumn{6}{|l|}{ Technical } \\
\hline $\begin{array}{l}\text { Shared electronic } \\
\text { information exchange } \\
\text { system }\end{array}$ & $\begin{array}{l}\text { Multi-disciplinary } \\
\text { collaboration }\end{array}$ & $\begin{array}{l}\text { Shared electronic patient } \\
\text { information system }\end{array}$ & $\begin{array}{l}\text { Electronic notifications to primary care } \\
\text { providers to inform them about patient } \\
\text { hospital visits and to provide them } \\
\text { (web-based) access to available discharge } \\
\text { information }\end{array}$ & $65,66,71-73$ & $1 b$ \\
\hline \multicolumn{6}{|l|}{ Patient and relative } \\
\hline $\begin{array}{l}\text { Participation in the } \\
\text { discharge process }\end{array}$ & $\begin{array}{l}\text { Self- } \\
\text { management/ } \\
\text { Guided practice }\end{array}$ & $\begin{array}{l}\text { Encouraging and facilitating } \\
\text { patients in self-management } \\
\text { skills }\end{array}$ & $\begin{array}{l}\text { Provide patient with discharge record (e. } \\
\text { g., active problem list, medication, } \\
\text { allergies, patient concerns) owned and } \\
\text { maintained by the patient to facilitate } \\
\text { cross-site information transfer }\end{array}$ & $62,74,75$ & $1 b$ \\
\hline $\begin{array}{l}\text { Skills and dare to speak } \\
\text { up }\end{array}$ & $\begin{array}{l}\text { Coaching/ } \\
\text { Guided practice }\end{array}$ & $\begin{array}{l}\text { Encouragement to assert a } \\
\text { more active role during } \\
\text { discharge }\end{array}$ & Question form for patients & 74 & $1 b$ \\
\hline $\begin{array}{l}\text { Understanding of medical } \\
\text { history and/or medication }\end{array}$ & $\begin{array}{l}\text { Guided practice/ } \\
\text { Knowledge } \\
\text { transfer }\end{array}$ & $\begin{array}{l}\text { Medication counseling at the } \\
\text { hospital at discharge or at the } \\
\text { patient's home }\end{array}$ & Visits by a pharmacist counselor & 76 & $1 b$ \\
\hline
\end{tabular}

the development of their intervention. The list of all identified strategies and related materials, level of evidence and references are available upon request.

Many interventions were evaluated in well-designed studies. For example, the use of standardised discharge practices such as the use of discharge letter templates, discharge planning guidelines and medication reconciliation checklists are effective strategies [65-67,70]. The use of a shared electronic patient information platform facilitates discharge communication between hospital and primary care providers [66,71-73]. There is evidence demonstrating that the patient's role in the discharge process is enhanced by the provision of written and verbal discharge information and by assistance and guidance in selfmanagement (e.g., discharge counselling, follow-up calls or home-based visits and a patient discharge record or question form) [74,76]. However, many promising interventions have not been evaluated properly or were tested using weak study designs. For example, the effects of lectures and exercises on discharge practice in the medical curriculum, and regular group discussions involving hospital and primary care providers are largely unknown [52].

Moreover, there is limited evidence on the effects of reinforcement by using discharge planning reminders, mandatory administrative tasks or financial incentives and penalties [77].

Insight also lacks into the effects of strategies to increase care provider reflections on discharge practices (e.g., use of a standardised feedback form, video reflection, role play or simulation of discharge consultations) [52] and regarding the use of teach-back to check the patient's understanding of their medical and medication history $[63,78]$.

\section{Steps 5 and 6: Implementation and evaluation}

Commitment from and ownership by the target group is essential to successful implementation $[79,80]$. The awareness among end users is enhanced when they are directly involved in the development or modification of the innovation, in mounting the implementation plan, and in selecting the implementation strategies to be used [35].

Moreover, uptake of policies and protocols, reimbursement and the consideration of patients' preferences are necessary for a sustainable implementation [81].

Strategies that address the barriers to change are required to implement interventions in daily practice [36]. Most theories on implementing interventions in health care emphasise that an analysis of the barriers to change practice is a prerequisite to selecting or developing an effective implementation strategy [17]. An implementation plan should be developed specifically after selecting the implementation strategies to tackle the barriers. This plan should be compatible with the target group and settings in which the implementation will take place. Good management and planning of implementation activities (i.e., what, when, where, how and by whom) also appears to be a requisite for successful implementation of innovations in patient care [35]. 
Formative and summative effect evaluation should be carried out using hospital readmission and adverse events as defined patient outcome effects to evaluate whether the intervention led to the desired degree of change. The formulated performance objectives in step 2 can be operationalised in measurable process indicators, for example by assessing the proportion of patients discharged with a complete discharge letter and assessing the proportion of patients discharged after medication reconciliation.

A process evaluation should be performed to understand the effect, success or failure of the intervention and to get an impression of its feasibility, generalizability and its acceptability in the target population. The process evaluation gives insight into the black box of the implementation process and can explain the variation in results in evaluating interventions. The activities carried out as part of the intervention, the actual exposure of participants to these activities, and their experience of these activities should be studied [40].

\section{Discussion}

Effective hospital discharge and reducing patient readmission rates are influenced by the behaviours of care providers and patients and their environmental context. Our findings demonstrate the existence of a large number of determinants for (in)effective discharge that underscore the complexity of the discharge process. Therefore, improving hospital discharge requires a multicomponent, multi-level intervention ("bundle") instead of trying to find a "magic bullet" single intervention.

An extensive overview of theory-based methods and practical strategies suitable for improving patient handover skills and healthcare provider and patient behaviour in the discharge process was systematically created based on the scale, causes, and consequences of ineffective hospital discharge presented in our study. Most interventions were aimed at improving the organisational and technical aspects of the discharge process. There is a lack of evidence-based interventions on improving healthcare provider skills by means of handover training and evidence-based guidance. Moreover, effective interventions for changing the individual healthcare provider's and patient's competencies, awareness and attitudes (e.g., via education, reminders or teach-back), and the relationship between providers (e.g., via frequent informal meeting between hospital and primary care providers and reflexive feedback) are lacking. All this despite our overwhelming data demonstrating that awareness, attitudes and skills are key factors for improving hospital discharge. We found a gap between the discharge improvement needs and the evidence-based interventions that are suitable to address these needs. The lack of evidence about the effectiveness of interventions may be attributed to the difficulty of measuring attitudes and their effects on healthcare performance [82-84].

This study is supported by earlier research and discharge programs in the United States: i.e., the RED ("ReEngineerd Discharge") project $[69,85]$, the Care Transitions Program [86] and BOOST (Better Outcomes for Older adults through Safe Transitions) [87]. An important strength of our study is the deliberate assessment of determinants and interventions that affect the discharge process. Qualitative input provides comprehensive insights into a variety of determinants. Our empirical data, results of a systematic literature review, theories of social behaviour and multiple consultation rounds of a broad group of 324 experts (researchers, policy-makers, inspectors) in the field of quality and safety in healthcare, healthcare providers and patient representatives [31], provided useful input for the selection of change methods, practical strategies and related evidence.

A limitation of the study is our focus on the microlevel excluding other key factors for change. The possible barriers and facilitators at a macro- and meso-levels, i.e., financial and legal obligations or constrains were not included. Moreover, the relationships between the identified determinants and theoretical-based methods and strategies were hypothetical.

However, the determinants were systematically and theory-driven and linked to practical strategies using the IM method and were not intuitively chosen.

\section{Conclusions}

This study provides a comprehensive overview of patient discharge problems and underlying causes. It provides a guiding framework including theory-based strategies and practical tools to support care providers and policymakers in their efforts to select and implement interventions on a more rational basis. Intervention mapping is a powerful method for care providers and policy makers to assess and prioritise intervention strategies and tailor them to the needs of individual facilities and healthcare systems. The next step for care providers and policymakers is to look carefully into the discharge problems in their own local settings and to select appropriate solutions for improving hospital discharge effectively.

\section{Additional files}

Additional file 1: Modified model based on PRECEDE-PROCEED concept and the theory of planned behavior

Additional file 2: Study Population Inclusion and Exclusion Criteria.

Additional file 3: Matrix of change objectives.

\section{Competing interests}

The authors declare that they have no competing interests. 


\section{Authors' contributions}

$\mathrm{GH}$ and $\mathrm{MZ}$ designed and managed the study. GH, MF, ED-U, CO and GT collected the data. All authors $(G H, M Z, M V D, P B, C K, M F, G O ̈, M O, S B, C O, R S$, $\mathrm{GT}, \mathrm{FV}, \mathrm{EDU}, \mathrm{LS}, \mathrm{HW}$ ) were involved in the analysis and interpretation of the data. GH and MZ drafted the manuscript. All authors read the manuscript for important intellectual content and approved the final version.

\section{Acknowledgements}

We thank the patients, relatives, physicians and nurses who participated in this study. We also thank the 220 expert meeting participants for their contributions to this study.

\section{Financial support}

This work was supported by a grant from the European Union, the Framework Programme of the European Commission (FP7-HEALTH-F2-2008223409).

\section{Author details}

'Radboud University Medical Center, Scientific Institute for Quality of Healthcare (IQ healthcare), 114 IQ healthcare, P.O. Box 9101, 6500 HB, Nijmegen, The Netherlands. ${ }^{2}$ Radboud University Medical Center, Kalorama Foundation, Nijmegen, The Netherlands. ${ }^{3}$ Radboud University Medical Center, Department of Primary Care, Nijmegen, The Netherlands. ${ }^{4}$ Patient Safety Center, University Medical Center Utrecht, Utrecht, The Netherlands. ${ }^{5}$ Department of Health Studies, University of Stavanger, Stavanger, Norway. ${ }^{6}$ University College Cork, Cork, Ireland. ${ }^{7}$ Department of Neurobiology, Care Sciences and Society, Karolinska Institutet, Stockholm, Sweden. ${ }^{8}$ Department of Social Work, Karolinska University Hospital, Stockholm, Sweden. ${ }^{9}$ Department of Clinical Science, Intervention and Technology, Karolinska Institutet, Stockholm, Sweden. ${ }^{10}$ Quality and Patient Safety, Karolinska University Hospital, Stockholm, Sweden. ${ }^{11}$ Department of Emergency Medicine, Karolinska University Hospital, Stockholm, Sweden. ${ }^{12}$ Avedis Donabedian Institute, Universidad Autónoma de Barcelona, Barcelona, Spain. ${ }^{13}$ Clinical Risk Management and Patient Safety Centre, Tuscany region, Italy.

${ }^{14}$ National Center for Quality Assessment in Health Care, Krakow, Poland.

Received: 19 March 2014 Accepted: 10 September 2014

Published: 13 September 2014

\section{References}

1. Halasyamani L, Kripalani S, Coleman E, Schnipper J, van Walraven C, Nagamine J, Torcson P, Bookwalter T, Budnitz T, Manning D: Transition of care for hospitalized elderly patients - development of a discharge checklist for hospitalists. J Hosp Med 2006, 1:354-360.

2. Clare J, Hofmeyer A: Discharge planning and continuity of care for aged people: indicators of satisfaction and implications for practice. Aust J Adv Nurs 1998, 16:7-13.

3. Hellesø R, Lorensen $M$, Sorensen $L$ : Challenging the information gap-the patients transfer from hospital to home health care. Int J Med Inform 2004, 73:569-580.

4. Cohen SG, Bailey DE: What makes teams work: group effectiveness research from the shop floor to the executive suite. J Manag 1997, 23:239-290.

5. Cheah LP, Amott DH, Pollard J, Watters DAK: Electronic medical handover: towards safer medical care. Med J Aust 2005, 183:369-372.

6. Simpson K: Handling handoffs safely. MCN Am J Matern Child Nurs 2005, 30:152.

7. Friedman B, Basu J: The rate and cost of hospital readmissions for preventable conditions. Med Care Res Rev 2004, 61:225-240.

8. Foekema H, Hendrix C: Mistakes Are Expensive, An Investigation Into Medical Transcription Errors, (Part 2). In Fouten Worden Duur Betaald, Een Onderzoek Naar Medische Overdrachtsfouten (Deel 2). Amsterdam: TNS NIPO; 2004.

9. Leendertse AJ, Egberts AC, Stoker L, van den Bemt PM, HARM Study Group: Frequency of and risk factors for preventable medication-related hospital admissions in the Netherlands. Arch Intern Med 2008, 168:1890-1896.

10. Hansagi H, Olsson M, Glas S, Flink M, Barach P, Öhlén G: Report on the Barriers And Facilitators To Effective Handovers In The Social, Linguistic And Technological Context In Which They Take Place. Utrecht, The Netherlands: Utrecht 383 Medical Center; 2010.
11. Johnson JK, Farnan JM, Barach $P$, Hesselink $G$, Wollersheim $H$, Pijnenborg $L$, Kalkman C, Arora VM, HANDOVER Research Collaborative: Searching for the missing pieces between hospital and primary care: mapping the patient process during care transitions. BMJ Qual Saf 2012, 21(Suppl 1):i97-i105. [published online ahead of print]

12. Hesselink G, Vernooij-Dassen M, Pijnenborg L, Barach P, Gademan P, DudzikUrbaniak E, Flink M, Orrego C, Toccafondi G, Johnson JK, Schoonhoven L, Wollersheim H, European HANDOVER Research Collaborative: Organizational culture: an important context for addressing and improving hospital to community patient discharge. Med Care 2012, 51:90-98.

13. Craig P, Dieppe P, Macintyre S, Michie S, Nazareth I, Petticrew M, Medical Research Council Guidance: Developing and evaluating complex interventions: the new Medical Research Council guidance. BMJ 2008, 337:a1655.

14. Davis DA, Thomson MA, Oxman AD, Haynes RB: Changing physician performance. A systematic review of the effect of continuing medical education strategies. JAMA 1995, 274:700-705.

15. Wensing $M$, van der Weijden T, Grol R: Implementing guidelines and innovations in general practice: which interventions are effective? $\mathrm{Br} J$ Gen Pract 1998, 48:991-997.

16. van Bokhoven MA, Kok G, van der Weijden T: Designing a quality improvement interventions: a systematic approach. Qual Saf Health Care 2003, 12:215-220

17. Baker R, Camosso-Stefinovic J, Gillies C, Shaw EJ, Cheater F, Flottorp S, Robertson N: Tailored interventions to overcome identified barriers to change: effects on professional practice and health care outcomes (Review). Cochrane Database Syst Rev 2010, 区(3), CD005470.

18. Bartholomew LK, Parcel GS, Kok G: Planning Health Promotion Programs. An Intervention Mapping Approach. Thirdth edition. San Francisco: Jossey-Bass; 2011.

19. Mullen PD, DiClemente CC, Bartholomew LK: Theory and Context In Project PANDA: A Program To Help Postpartum Women Stay Off Cigarettes. In Intervention Mapping: Designing Theory And Evidence-Based Health Promotion Programs. Edited by Bartholomew LK, Parcel GS, Kok G, Gottlieb NH. Mountain View, CA: Mayfield Publishing Co:; 2001.

20. Schmid AA, Andersen J, Kent T, Williams LS, Damush TM: Using intervention mapping to develop and adapt a secondary stroke prevention program in Veterans Health Administration medical centers. Implement Sci 2010, 5:97.

21. Fernandez ME, Bartholomew LK, Lopez A, Parcel G: Using Intervention Mapping In The Development Of A School-Based Asthma Management Intervention For Latino Children And Families: The FAMILIAS Project. In 128th annual meeting of the American Public Health Association. 2000.

22. van Empelen P, Kok G, Schaalma HP, Bartholomew LK: An AIDS riskreduction program for Dutch drug users: an intervention mapping approach to planning. Health Promot Pract 2003, 4:402-412.

23. Heinen MM, Bartholomew LK, Wensing $M$, van de Kerkhof $P$, van Achterberg T: Supporting adherence and healthy lifestyles in leg ulcer patients: systematic development of the lively legs program for dermatology outpatient clinics. Patient Educ Couns 2006, 61:279-291.

24. Green LW, Kreuter MW: Health Promotion Planning: An Educational And Ecological Approach. 3rd edition. Mountain View, CA: Mayfield Publishing Co.; 1999.

25. Yao GL, Novielli N, Manaseki-Holland S, Chen YF, van der Klink M, Barach P, Chilton PJ, Lilford RJ, European HANDOVER Research Collaborative: Evaluation of a predevelopment service delivery intervention; an application to improve clinical handovers. BMJ Qual Saf 2012, 21:i29-i38.

26. Corbin J, Strauss A: Grounded theory research: procedures, canons, and evaluative criteria. Qual Sociol 1990, 13:3-21.

27. Barach P, Gademan P, Kalkman C, Johnson JK, Pijnenborg L: Report on How Variations In Handover Processes Lead To Near Misses And Adverse Outcomes, And Identifying Standardized Elements Of Communication. Utrecht, The Netherlands: Utrecht Medical Center, for the European Union; 2010.

28. McEachan RR, Lawton RJ, Jackson C, Conner M, Lunt J: Evidence. Theory and context: using intervention mapping to develop a worksite physical activity intervention. BMC Public Health 2008, 8:326.

29. van Achterberg T, Huisman-de Waal GG, Ketelaar NA, Oostendorp RA, Jacobs JE, Wollersheim H: How to promote healthy behaviours in patients? An overview of evidence for behaviour change techniques. Health Promot Int 2010, 26:148-162. 
30. Grol RP, Bosch MC, Hulscher ME, Eccles MP, Wensing M: Planning and studying improvement in patient care: the use of theoretical perspectives. Milbank Q 2007, 85:93-138.

31. Kutryba B, Dudzik-Urbaniak E, Göbel AA, Pijnenborg L, Barach P. Dissemination of the HANDOVER project - Final Report. Utrecht, The Netherlands: Utrecht Medical Center, for the European Union; 2011.

32. Hesselink G, Schoonhoven L, Barach P, Spijker A, Gademan P, Kalkman C, Liefers J, Vernooij-Dassen M, Wollersheim H: Improving patient handovers from hospital to primary care. A systematic review. Ann Intern Med 2012, 157:417-428.

33. Oxford Centre of Evidence-Based Medicine. [http://www.cebm.net/index. aspx?o=1025]

34. Cabana MD, Rand CS, Powe NR, Wu AW, Wilson MH, Abboud PA, Rubin HR: Why don't physicians follow clinical practice guidelines? A framework for improvement. JAMA 1999, 282:1458-1465.

35. Grol R, Wensing M, Eccles M, Davis D: Improving Patient Care: The Implementation Of Change In Health Care. secondth edition. Wiley-Blackwell: Elsevier; 2013.

36. Grimshaw JM, Thomas RE, MacLennan G, Fraser C, Ramsay CR, Vale L, Whitty P, Eccles MP, Matowe L, Shirran L, Wensing M, Dijkstra R, Donaldson C: Effectiveness and efficiency of guideline dissemination and implementation strategies. Health Tech Ass 2004, 8:1-72.

37. Clarke CM, Persaud DD: Leading clinical handover improvement: a change strategy to implement best practices in the acute care setting. J Patient Saf 2011, 7:11-18.

38. Australian Medical Association: Safe Handover: Safe Patients, Guidance On Clinical Handover For Clinicians And Managers. Canberra: AMA; 2006.

39. Brown C, Hofer T, Johal A, Thomson R, Nicholl J, Franklin BD, Lilford RJ: An epistemology of patient safety research: a framework for study design and interpretation. Part 2. Study design. Qual Saf Health Care 2008, 17:163-169.

40. Hulscher ME, Laurant MG, Grol RP: Process evaluation on quality improvement interventions. Qual Saf Health Care 2003, 12:40-46.

41. Forster AJ, Murff HJ, Peterson JF, Gandhi TK, Bates DW: The incidence and severity of adverse events affecting patients after discharge from the hospital. Ann Intern Med 2003, 138:161-167.

42. Halfon P, Eggli Y, van Melle G, Chevalier J, Wasserfallen JB, Burnand B: Measuring potentially avoidable hospital readmissions. J Clin Epidemiol 2002, 55:573-587.

43. Jencks SF, Williams MV, Coleman EA: Rehospitalizations among patients in the Medicare fee-for-services program. N Engl J Med 2009, 360:1418-1428.

44. Jencks SF: Defragmenting care. Ann Intern Med 2010, 153:757-758.

45. Bandura A: Social Foundations Of Thought And Action. A Social Cognitive Theory. Englewood Cliffs, New Jersey: Prentice Hall; 1986.

46. Prochaska J, DiClimente C, Norcross J: In search of how people change. Applications to addictive behaviors. Am Psychol 1992, 47:1102-1114.

47. Prochaska JO, DiClemente CC: The Transtheoretical Approach. In Handbook of Psychotherapy Integration. 2nd edition. Edited by Norcross JC, Goldfried MR. New York: Oxford University Press; 2005.

48. Pettigrew TF, Tropp LR: When Groups Meet: The Dynamics Of Intergroup Contact. New York: Psychology Press; 2011

49. Locke EA, Latham GP: A Theory Of Goal Setting And Task Performance. Englewood Cliffs, NJ: Prentice-Hall; 1990

50. Locke EA, Latham GP: Building a practically useful theory of goal setting and task motivation: a 35-year odyssey. Am Psychol 2002, 57:701-717.

51. Wagner $\mathrm{EH}$ : The role of patient care teams in chronic disease management. BMJ 2000, 320:569-572.

52. Gordon M, Findley R: Educational interventions to improve handover in health care: a systematic review. Med Educ 2011, 45:1081-1089.

53. Chiu WK, Newcomer R: A systematic review of nurse-assisted case management to improve hospital discharge transition outcomes for the elderly. Professional Case Management 2007, 12:330-336

54. Caplan GA, Williams AJ, Daly B, Abraham K: A randomized, controlled trial of comprehensive geriatric assessment and multidisciplinary intervention after discharge of elderly from the emergency department-the DEED II study. J Am Geriatr Soc 2004, 52:1417-1423.

55. Naylor MD, Brooten D, Campbell R, Jacobsen BS, Mezey MD, Pauly MV, Schwartz JS: Comprehensive discharge planning and home follow-up of hospitalized elders: a randomized clinical trial. JAMA 1999, 281:613-620.

56. Rich MW, Vinson JM, Sperry JC, Shah AS, Spinner LR, Chung MK, DavilaRoman V: Prevention of readmission in elderly patients with congestive heart failure: results of a prospective, randomized pilot study. J Gen Intern Med 1993, 8:585-590.
57. Crotty M, Rowett D, Spurling L, Giles LC, Phillips PA: Does the addition of a pharmacist transition coordinator improve evidence-based medication management and health outcomes in older adults moving from the hospital to a long-term care facility? Results of a randomized, controlled trial. Am J Geriatr Pharmacother 2004, 2:257-264.

58. Preen DB, Bailey BE, Wright A, Kendall P, Phillips M, Hung J, Hendriks R, Mather A, Williams E: Effects of a multidisciplinary, post-discharge continuance of care intervention on quality of life, discharge satisfaction, and hospital length of stay: a randomized controlled trial. Int J Qual Health Care 2005, 17:43-51.

59. Avlund K, Jepsen E, Vass M, Lundemark H: Effects of comprehensive follow-up home visits after hospitalization on functional ability and readmissions among old patients. A randomized controlled study. Scand J Occup Ther 2002, 9:17-22.

60. Shyu Yl, Liang J, Wu CC, Su JY, Cheng HS, Chou SW, Chen MC, Yang CT, Tseng MY: Two-year effects of interdisciplinary intervention for hip fracture in older Taiwanese. J Am Geriatr Soc 2010, 58:1081-1089.

61. Rutherford A, Burge B: General practitioners and hospitals. Continuity of care Aust Fam Physician 2001, 30:1101-1107.

62. Balaban RB, Weissman JS, Samuel PA, Woolhandler S: Redefining and redesigning hospital discharge to enhance patient care: a randomized controlled study. J Gen Intern Med 2008, 23:1228-1233.

63. White M, Garbez R, Carroll M, Brinker E, Howie-Esquivel J: Is "Teach-Back" Associated With Knowledge Retention and Hospital Readmission in Hospitalized Heart Failure Patients? J Cardiovasc Nurs 2013, 28:137-147.

64. van Walraven C, Laupacis A, Seth R, Wells G: Dictated versus databasegenerated discharge summaries: a randomized clinical trial. CMAJ 1999, 160:319-326.

65. Schnipper JL, Kirwin JL, Cotugno MC, Wahlstrom SA, Brown BA, Tarvin E, Kachalia A, Horng M, Roy CL, McKean SC, Bates DW: Role of pharmacist counseling in preventing adverse drug events after hospitalization. Arch Intern Med 2006, 166:565-571.

66. Graumlich JF, Novotny NL, Nace GS, Aldag JC: Patient and physician perceptions after software-assisted hospital discharge: cluster randomized trial. J Hosp Med 2009, 4:356-363.

67. King TL: The impact of a nurse-driven evidence-based discharge planning protocol on organizational efficiency and patient satisfaction in patients with cardiac implants. University of Central Florida: PhD dissertation; 2008.

68. Bump GM, Bost JE, Buranosky R, Elnicki M: Faculty member review and feedback using a sign-out checklist: improving intern written sign-out. Acad Med 2012, 87:1125-1131.

69. Jack BW, Chetty VK, Anthony D, Greenwald JL, Sanchez GM, Johnson AE, Forsythe SR, O'Donnell JK, Paasche-Orlow MK, Manasseh C, Martin S, Culpepper $L$ : A reengineered hospital discharge program to decrease rehospitalization: a randomized trial. Ann Intern Med 2009, 150:178-187

70. Koehler BE, Richter KM, Youngblood L, Cohen BA, Prengler ID, Cheng D, Masica AL: Reduction of 30-day postdischarge hospital readmission or emergency department (ED) visit rates in high-risk elderly medic. $J$ Hosp Med 2009, 4(4):211-218.

71. Tripp JS: Development And Evaluation Of Notifications To Inform Primary Care Providers Of Summary Documentation For Their Patients' Hospital Visits. The University of Utah: PhD dissertation; 2009.

72. Chen Y, Brennan N, Magrabi F: Is email an effective method for hospital discharge communication? A randomized controlled trial to examine delivery of computer generated discharge summaries by email, fax, post and patient hand delivery. Int J Med Inform 2010, 79:167-172.

73. Afilalo M, Lang E, Léger R, Xue X, Colacone A, Soucy N, Vandal A, Boivin JF, Unger $B$ : Impact of a standardized communication system on continuity of care between family physicians and the emergency department. CJEM 2007, 9:79-86

74. Coleman EA, Parry C, Chalmers S, Min SJ: The care transitions intervention: results of a randomized controlled trial. Arch Intern Med 2006, 166:1822-1828.

75. Krumholz HM, Amatruda J, Smith GL, Mattera JA, Roumanis SA, Radford MJ, Crombie $\mathrm{P}$, Vaccarino V: Randomized trial of an education and support intervention to prevent readmission of patients with heart failure. $J \mathrm{Am}$ Coll Cardiol 2002, 39:83-89.

76. Hugtenburg JG, Borgsteede SD, Beckeringh JJ: Medication review and patient counselling at discharge from the hospital by community pharmacists. Pharm World Sci 2009, 31:630-637. 
77. Kaiser Health News. Medicare To Penalize 2,217 Hospitals for Excess Readmissions. [http://www.kaiserhealthnews.org/stories/2012/august/13/ medicare-hospitals-readmissions-penalties.aspx]

78. Schillinger D, Piette J, Grumbach K, Wang F, Wilson C, Daher C, Leong-Grotz K, Castro C, Bindman AB: Closing the loop. Physician communication with diabetic patients who have low health literacy. Arch Intern Med 2003, 163:83-90.

79. Dixon-Woods M, McNicol S, Martin G: Ten challenges in improving quality in healthcare: lessons from the Health Foundation's programme evaluations and relevant literature. BMJ Qual Saf 2012, 21:876-884

80. Weiner BJ: A theory of organizational readiness for change. Implement Sci 2009, 4:67.

81. Naylor MD, Aiken LH, Kurtzman ET, Olds DM, Hirschman KB: The care span: the importance of transitional care in achieving health reform. Health Aff (Millwood) 2011, 30:746-754.

82. Parmelli E, Flodgren G, Beyer F, Baillie N, Schaafsma ME, Eccles MP: The effectiveness of strategies to change organisational culture to improve healthcare performance: a systematic review. Implement Sci 2011, 6:33.

83. Scott T, Mannion R, Marshall M, Davies H: Does organisational culture influence health care performance? A review of the evidence. $J$ Health Serv Res Policy 2003, 8:105-117.

84. Gershon RR, Stone PW, Bakken S, Larson E: Measurement of organizational culture and climate in healthcare. J Nurs Admin 2004, 34:33-40.

85. Agency for Healthcare Research and Quality. [http://www.ahrq.gov/ professionals/systems/hospital/red/toolkit/index.html]

86. Division of Health Care Policy and Research, University of Colorado Denver. The Care Transitions Program. [www.caretransitions.org]

87. Society of Hospital Medicine. BOOSTing Care Transitions Resource Room. Philadelphia. [www.hospitalmedicine.org/ResourceRoomRedesign/ RR_CareTransitions/CT_Home.cfm]

doi:10.1186/1472-6963-14-389

Cite this article as: Hesselink et al.: Improving patient discharge and reducing hospital readmissions by using Intervention Mapping. BMC Health Services Research 2014 14:389.

\section{Submit your next manuscript to BioMed Central and take full advantage of:}

- Convenient online submission

- Thorough peer review

- No space constraints or color figure charges

- Immediate publication on acceptance

- Inclusion in PubMed, CAS, Scopus and Google Scholar

- Research which is freely available for redistribution 